\title{
Memoria, Patrimonio, Consumo y Olvido
}

\author{
Memory, Heritage, Consumption and Oblivion \\ Memória, Patrimônio, Consumo e Esquecimento
}

\author{
Juan Carlos Pérgolis Valsecchi; Arquitecto, M.Sc. en Arquitectura \\ Universidad Piloto de Colombia. Bogotá, Colombia \\ pergolisjuancarlos@yahoo.com \\ (i) https://orcid.org/0000-0002-2397-3812 \\ Estefanía Quijano Gómez; Arquitecta \\ Especialista en Economía Urbana y Regional \\ Universidad Externado de Colombia. Bogotá, Colombia \\ estefania.quijano12@hotmail.com \\ (iD) https://orcid.org/0000-0003-2758-9858
}

Recibido: septiembre 10 de 2020
Aceptado: noviembre 20 de 2020
Publicado: noviembre 30 de 2020

\section{RESUMEN}

La plaza-circo-teatro La Serrezuela, en Cartagena, un lugar para el disfrute colectivo, fue reemplazada por un centro comercial, con un simulacro de la vieja Plaza. El cambio del ritual comunitario del espectáculo, por el entretenimiento individualista del consumo, destruyó la pasión en todas las actividades. Varios edificios en Medellín y Bogotá fueron transformados y demolidos para dar paso a actividades basadas en el individualismo del esparcimiento como soporte del consumo. Edificios patrimoniales de gran presencia en la memoria urbana, representantes del espíritu del tiempo en cada ciudad, muestran que hay momentos de la historia en los que la sociedad escoge el olvido.

Palabras clave: Memoria; Patrimonio; Entretenimiento; Recorrido; Olvido.

\section{ABSTRACT}

The Plaza-circus-theater La Serrezuela, in Cartagena, a place for collective enjoyment, was replaced by a shopping center, with a simulation of the old Plaza. The change from the communal ritual of the spectacle to the individualistic entertainment of consumption destroyed passion in all activities. Several buildings in Medellín and Bogotá were transformed and demolished to give way to activities based on the individualism of leisure as a support for consumption. Heritage buildings with a great presence in urban memory, representatives of the spirit of time in each city, show that there are moments in history in which society chooses oblivion.

Keywords: Memory; Heritage; Entertainment; Travel; Oblivion. 


\section{RESUMO}

A praça-circo-teatro La Serrezuela, em Cartagena, um espaço de diversão coletiva, foi substituída por um centro comercial, com uma simulação da antiga praça. A mudança do ritual comunitário do espetáculo para o entretenimento individualista do consumo destruiu a paixão em todas as atividades. Vários edifícios em Medellín e Bogotá foram transformados e demolidos para dar lugar a atividades baseadas no individualismo do lazer como suporte para o consumo. Edifícios patrimoniais com grande presença na memória urbana, representantes do espírito do tempo em cada cidade, mostram que há momentos da história em que a sociedade opta por esquecer.

Palavras-chave: Memória, Patrimônio, Entretenimento, Viagem, Esquecimento.

\section{INTRODUCCIÓN}

Con frecuencia nos preguntamos si es posible preservar un bien patrimonial respetando su significación en la cultura del lugar, o si es posible preservarlo sin convertirlo en "entretenimiento", porque, aparentemente hoy, el único modo de mantener vivo un bien patrimonial es insertándolo arbitrariamente en el consumo.

El filósofo surcoreano y profesor de la Universidad de las Artes de Berlín, Byung-Chul Han (2018) señala que al ser humano de hoy le atraen las comunicaciones ligeras, sin ceremonias, sin pretensiones ni reglas, le atrae el "entretenimiento". En el marco de esta reflexión, se observa el nuevo centro comercial construido en el predio donde estuvo la vieja Plaza de toros-circo-teatro La Serrezuela, en Cartagena, y dos experiencias similares en Medellín: el Centro Comercial Villanueva, que resultó de una conversión del Seminario Mayor de esa ciudad, y la transformación del Palacio Nacional, obra del belga Agustín Goovaerts, también en centro comercial. En estos casos, el análisis semiótico explica el diferente reconocimiento social de cada una de estas dos obras porque, como lo sugirió Umberto Eco (1993), el significado de la Arquitectura lo define el usuario sobre el significante que propone el arquitecto (Pérgolis, 1995).

La observación en Medellín, concluye con otra obra de Agustín Goovaerts: el Edificio Mejía, que fue parte importante del paisaje cultural de esa ciudad y fue demolido, al igual que el Hotel Granada en Bogotá, obra-símbolo de la identidad de un momento que expresó la consolidación de la ciudad "cachaca".

Estos ejemplos evidencian la estrecha relación entre identidad, patrimonio, memoria y la relación de estos tres conceptos con el llamado "espíritu del tiempo" o Zeitgeist, expresión que engloba el conjunto de manifestaciones culturales de un momento (incluyendo la Arquitectura) y la fragilidad de los conceptos mencionados ente los violentos y rápidos cambios en nuestras sociedades.

\section{La Plaza-Circo-Teatro La Serrezuela, Cartagena} La Serrezuela, la vieja Plaza de toros y espectáculos de Cartagena, era una estructura de madera, deteriorada por el tiempo, el salitre del ambiente y el intenso uso, donde iba la comunidad a ver y criticar a algún cantante, de los buenos y conocidos que cada tanto llegaban a la ciudad, o de los no tan buenos ni tan conocidos, que abundaban, ocasionalmente; una bailarina con penachos de plumas pegoteadas por el salitre o, lo que parecía ser el objetivo principal de la Plaza, presenciar una corrida de toros, donde la alegría del grupo y el trago en botas de cuero predominaba sobre el espectáculo.

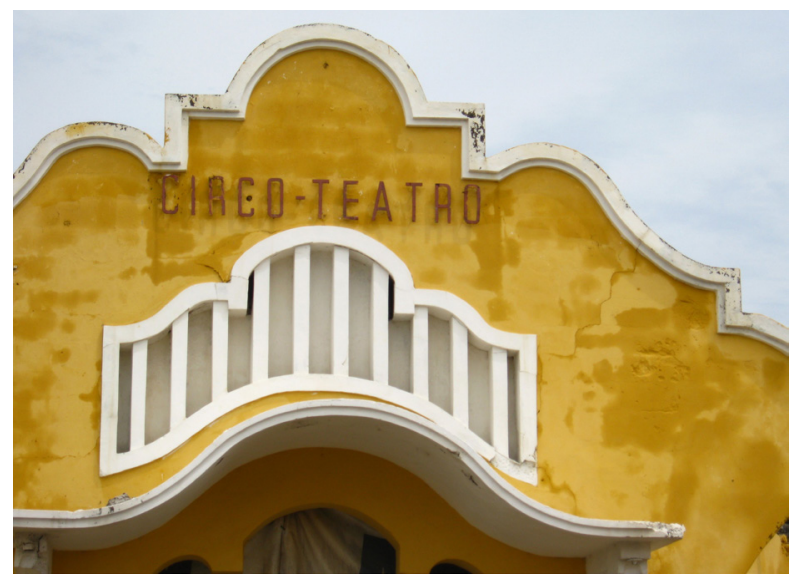

Figura 1. Plaza Teatro de Cartagena de Indias. Fuente: Somospartedelcuento (2012).

"La Plaza, además, estaba adornada de trencitas con cuencas de colores, atuendos y peinados exóticos, caderas alegres y anchas. Era una fiesta multicolor,' cuenta Moisés Díaz" (somospartedelcuento, 2012). 
Porque la fiesta en la vieja Plaza era comunitaria, colectiva, como lo era la alegría -o cualquier sentimiento- de la ciudad. Era el placer del ocio y el placer de la sociabilidad, que alcanzó su mayor expresión en aquel Festival de Música del Caribe de marzo de 1982, que rebasó el ámbito de la Plaza y se desparramó por toda la ciudad y toda la comunidad.

Hoy, sin embargo, el entretenimiento va más allá de los placeres del ocio o de la sociabilidad: el trabajo, la educación y hasta las ceremonias religiosa tienen que ser "entretenidos". Byung-Chul Han observa que ese afán destruyó la idea de pasión por el conocimiento, por el trabajo o por la fe religiosa; solo importa que, a través de las actividades, podamos establecer comunicaciones ligeras, light, sin pretensiones, sin ceremonias y por supuesto, sin reglas.

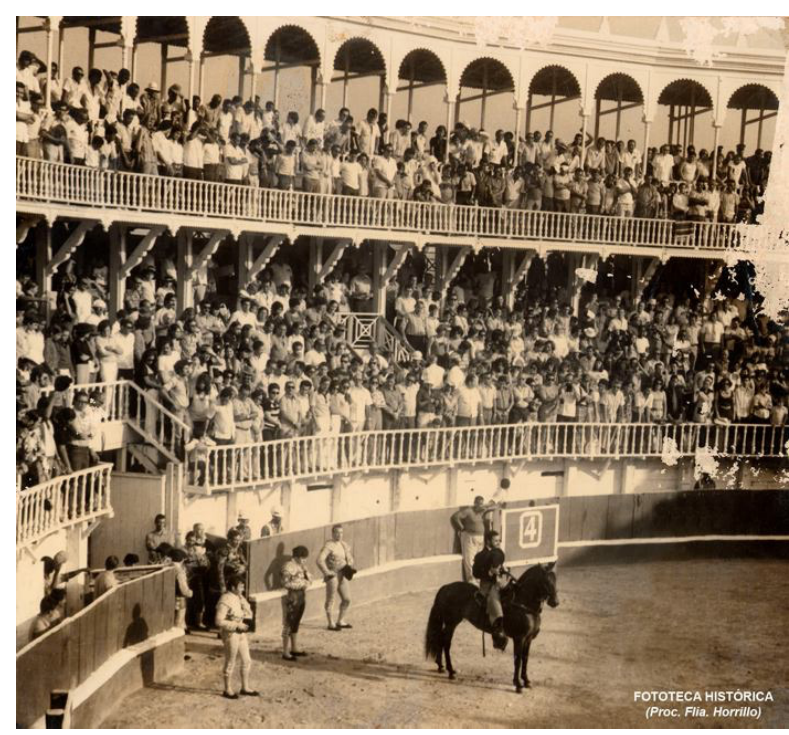

Figura 2. Plaza teatro de Cartagena de Indias. Fuente: Rodríguez (2012) Fototeca Histórica de Cartagena.

"Con esta placita no han podido ni el comején ni la carcoma, y mucho menos el desenfreno. Ahí está con sesenta y cinco años encima y adornando como histórica reliquia la ciudad amurallada" (Rodríguez, 2012).

Si en un momento se señaló que la realidad existe en la medida de nuestras pasiones (Pérgolis, 2000, p.19) esta integración del entretenimiento a todas las actividades de nuestra vida cambió lo real por los signos. Lo real: creó una realidad alternativa y fascinante ${ }^{1}$ que convirtió a las actividades en simulacros y como tal, carentes de sentido, pero capaces de satisfacer el deseo individual de entretenimiento.

Las fiestas no tienen que ver con el deseo individual, concluye Byung-Chul Han, por el contrario, en el juego colectivo -en la fiesta- los participantes se entregan a la pasión por las reglas, que son "lo colectivo" del juego. La memoria de la ciudad y la capacidad del espacio para narrar su historia están dados, tanto por el ámbito físico como por las experiencias asociadas a ello: los acontecimientos.

La Serrezuela, la plaza-circo-teatro fue el lugar ${ }^{2}$ del esparcimiento colectivo, de la fiesta, del juego de la comunidad, por eso fue un ícono o lugar insignia, imagen e identidad de la comunidad que consolidó lazos y pertenencia con el territorio.

Allí, en cada espectáculo que se presentaba, se integraba la comunidad y los ciudadanos se reconocían como parte de ella a través de la repetición de un ritual, incluso, aquel primer Festival de Música del Caribe de 1982, un evento nuevo en la Plaza y en la ciudad, pero amarrado a las reglas del juego entre la comunidad con el esparcimiento y su lugar (la Plaza) fue la mejor expresión de la importancia de los rituales y confirma la observación de Byung-Chun Han (2018) en relación con nuestra actual sociedad hipercomunicada, en la que día a día aumentan la soledad y el aislamiento: comunicación sin sociedad -define el autor- porque los rituales son acciones simbólicas que crean comunidad sin necesidad de comunicación.

En 1985, el Festival de Música del Caribe adquirió una especial relevancia y debió trasladarse a la nueva Plaza de toros, con mayor capacidad que La Serrezuela. Y la tradicional plaza-circo-teatro después de un tiempo fue olvidada, para dar paso a otros sitios de espectáculos y reunión cultural. El olvido trajo la ruina de la estructura de madera, con su estilo árabe y neomudéjar en los capiteles, arcadas y zócalos construidos, no por un arquitecto, sino por un carpintero, que en sus viajes recogió lenguajes y estilos para este icónico lugar que hoy es un hito en la memoria de quienes vivieron sus rituales.

1. En términos de Jean Baudrillard, el objetivo del simulacro es fascinar. 2. Los acontecimientos convierten al espacio en lugar (Pérgolis y Quijano, en revista Procesos Urbanos No5, 2019). 


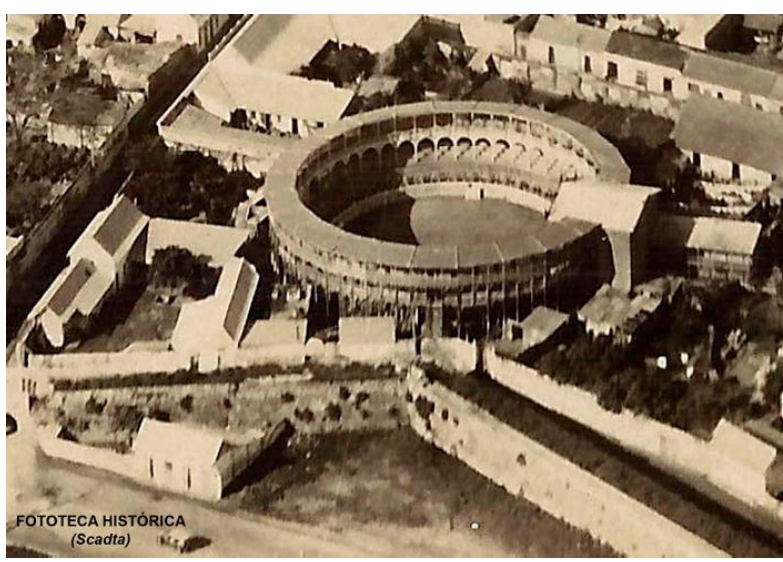

Figura 3. En 1893 se construyó la Plaza La Serrezuela. Después de la Guerra de los Mil Días la Plaza fue desmontada y, en 1908, los hermanos Vélez Daníes la construyeron nuevamente. Fuente: Fototeca Histórica de Cartagena / Archivo Scadta.

\section{El Centro Comercial La Serrezuela}

La Serrezuela es hoy un complejo comercial centro comercial, "shopping center"- de cuatro plantas, con locales comerciales, entretenimiento y gastronomía, con más 2.300 metros cuadrados de terrazas, con fuentes ornamentales y miradores, con almacenes internacionales y un cuidadoso trabajo de transmutación de la cultura tradicional basada en el entretenimiento por una secuencia de simulacros basados en el consumo. La vieja estructura de madera fue demolida y en su lugar el centro del complejo comercial- se construyó un simulacro de Plaza, también de madera, que quiere salvar el recuerdo de una cultura y un modo de entretenimiento, cosa que obviamente es imposible lograr. Allí en lo que fue la arena de aquella Plaza se reemplazó a los cantantes, a los teatreros y a las corridas de toros por una fuente con "aguas danzantes" y luces, que como en aquella película de Jacques Tati $^{3}$ se enciende, para las visitas, en determinados horarios.

Esta resignificación de la estructura patrimonial cambió el significado de lugar, que tenía el tradicional ámbito como sitio de encuentro de la comunidad para disfrute del entretenimiento colectivo, por otro significado en el que el entretenimiento, ahora ligado estrechamente al consumo, es una actividad individual. En el centro comercial cada uno se festeja a sí mismo, se exalta

3. Se refiere a "Mi tío" (Mon Oncle) película en la que Jacques Tati hace una sátira de la modernidad y la protagonista de una casa "ultra moderna" tiene en su jardín una fuente que sólo enciende cuando llegan visitas. el presente, lo cotidiano: el consumo y, si aparece algo nuevo, se lo trivializa con rapidez y se lo convierte en rutina, a diferencia de la experiencia comunitaria del entretenimiento en la plaza-circoteatro, donde cada presentación buscaba ser única $y$, como tal, trascender, ser parte de la memoria de la comunidad.

En el entretenimiento que posibilita el centro comercial no hay ritual, solamente hay satisfacción de deseos individuales, ya que el ritual, como evento colectivo, se basa en la repetición participativa con algo que está más allá de cada individuo, en nuestro caso los diferentes espectáculos que se presentaban y el sentido de colectividad que daba la participación: ir al lugar a presenciar el espectáculo.

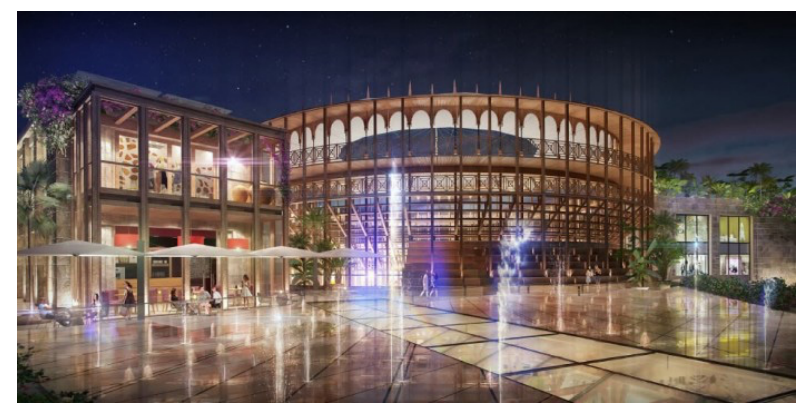

Figura 4. Visualización del proyecto para la Plaza La Serrezuela. Fuente: Covo (2017).

La tal "salvación del inmueble, fue un simple pretexto para realizar un proyecto netamente comercial que violó la norma vigente en materia de alturas, usos y respeto a la zona de influencia de un Bien de Interés Cultural..." Covo (2012).

¿Qué puede significar esta nueva Plaza-comercio de la Serrezuela, que ya no es plaza, ni circo, ni teatro? ¿Es una "puesta al día" de Cartagena en relación con otros destinos turísticos? ¿O es simplemente un golpe a la memoria y a la evocación de una Cartagena que cada día se desdibuja más? Maurice Halbwachs (1925), señala que recordar es el acto de representar en la imaginación lo vivido en otro momento. Entonces... ¿qué se quiere recordar ahora en el centro comercial La Serrezuela? ¿Cómo se recuerdan las nuevas cosas, los nuevos lugares? Ante estas preguntas, no se puede olvidar la frase de Marco Romano (1985), el teórico italiano, que proponía que las cosas colectivas deben mostrarse como algo que viene de lejos y va lejos, es decir, con historia y con futuro, porque nadie confiaría su 
sentimiento de identidad -que es seguridad en sí mismo- en algo recién inventado.

\section{El Monumento y la Memoria en la Ciudad Turística}

La memoria de un pueblo es siempre múltiple, rodeada de contradicciones, superposiciones y multiplicidad de sentidos, Pierre Nora, (2006) indica que "la memoria, por naturaleza, es afectiva, emotiva, abierta a todas las transformaciones, inconsciente de sus sucesivas transformaciones, vulnerable a toda manipulación, susceptible de permanecer latente durante largos períodos y de bruscos despertares".

La memoria se representa en lugares como una realidad simbólica y busca ser descubierta más allá de su realidad histórica (Nora,1998). Estos lugares pueden ser edificios, museos, los tan de moda centros de memoria, o monumentos, entre otra amplia gama de objetos posibles. Estos lugares o representaciones funcionan como marcas en el territorio que conmemoran el pasado a través de lo urbano.

La plaza-circo-teatro La Serrezuela era una de estas marcas que conmemoraba el pasado y mantenía un horizonte de sentido que se extendía gran parte del sector de San Diego: desde la placita homónima hasta la muralla. El monumento, la vieja plaza-patrimonio, rebasaba su identidad, iba más allá de sí misma y el lugar de la memoria, era un sector de la ciudad, porque allí ocurría la fiesta, allí iba la comunidad a encontrarse en el ritual, a ser parte del acontecimiento.

Así, el sector de la Serrezuela, en el barrio de San Diego se convirtió en lugar de la memoria, porque haber tenido lugar es tener un lugar (Sztulwark P., 2006) o, lo que es lo mismo: haber sucedido es haber marcado un lugar y como escribió Estela Mansilla Decesari (2011). "Estos sitios de memoria, que marcan, en número cada vez más significativo, la piel de la tierra pueden y deben actuar como recuerdo y como advertencia". La última corrida de toros en la Plaza fue en 1972 y el último acontecimiento significativo fue el Festival de Música del Caribe desde 1982 hasta 1985, cuando, por razones de aforo, se trasladó a la nueva Plaza de Toros, fuera del recinto amurallado.

Nunca se debe olvidar que la cultura es identidad, y por tanto es orgullo de la comunidad, por lo que jamás debe ser considerada como una forma de riqueza material negociable (Borrega Reyes, 2009) aunque sean lugares inestables y con fácil tendencia al cambio y a la resignificación, como en este caso, la plaza-circo-teatro; de estos lugares se agarra el turismo como manifestación social y cultural para sumergirse en el mundo simbólico y de significación, de manera que, por un lado, está la dimensión material de los monumentos y edificios; $y$, por otro, el componente simbólico (Fainstein y Gladstone, 1999) desde donde los ciudadanos, la comunidad, tiene la capacidad de representar los lazos interpersonales y la demostración de los valores culturales. Puede afirmarse, entonces, como proponen Lash y Urry, que "el turista consume servicios y experiencias que convierten en signos: hace un trabajo de transformación semiótica" (Lash, Urry, 1997; Palacios, 2010).

La demolición de la plaza-circo-teatro y su remplazo por un centro comercial con un simulacro de plaza no indujo a una transformación semiótica: creó un nuevo signo basado en el consumo y el entretenimiento y -de acuerdo con Eco- si el primer significado de la Arquitectura surge de su función, la nueva función comercial con sus connotaciones (consumo, individualismo, etc.) impidió la transformación semiótica, creó un nuevo signo, aunque pretendidamente se lo haya maquillado del anterior. El objetivo del simulacro es fascinar, señaló Baudrillard (1981) y, sin dudas, el simulacro de plaza en el centro comercial cambió la realidad del viejo edificio por los signos fascinantes de una realidad alternativa, pero estos nuevos signos, referidos al consumo de entretenimiento, confunden y aniquilan la memoria del patrimonio.

Una Observación en Dos Intervenciones en Medellín: Centro Comercial Villanueva y Centro Comercial Palacio Nacional

Observemos dos edificios de gran presencia urbana y de importancia patrimonial, porque expresan el espíritu del tiempo y el paisaje cultural de Medellín en la primera mitad del siglo XX, cuando en la ciudad era evidente el deseo de modernidad, a la vez que mantenía un profundo arraigo por la tradición.

La modernidad en la vida y en el paisaje de la ciudad entró a Medellín en las primeras décadas del siglo XX, acompañadas por el desarrollo comercial. La tipología de comercio urbano con vitrina a la calle en edificios de dos o tres pisos de vivienda, conformó el centro de la ciudad dinámico y vital, el espacio para el paseo: salir a las calles del centro a 
caminar y mirar vitrinas; como después en los años ochenta y noventa del siglo XX lo intentaron recrear los centros comerciales.

Pero, también hay que reconocer la profunda religiosidad del pueblo antioqueño, presente en todos los rasgos de la vida. Patricia Londoño Vélez (1995) cita a J.M. Torres Caicedo en su viaje a Medellín en 1857: "El pueblo de Medellín, como en general el del Estado de Antioquia, es esencialmente religioso, y prefiere las ceremonias religiosas a los bailes y los espectáculos". Más adelante, la autora señala: "El repique de las campanas constituía una referencia importante en la rutina diaria de los medellinenses, pues todos los días a la misma hora llamaban a misa y anunciaban el ángelus, el trisagio y los servicios religiosos; en ocasiones especiales podían expresar otros mensajes".

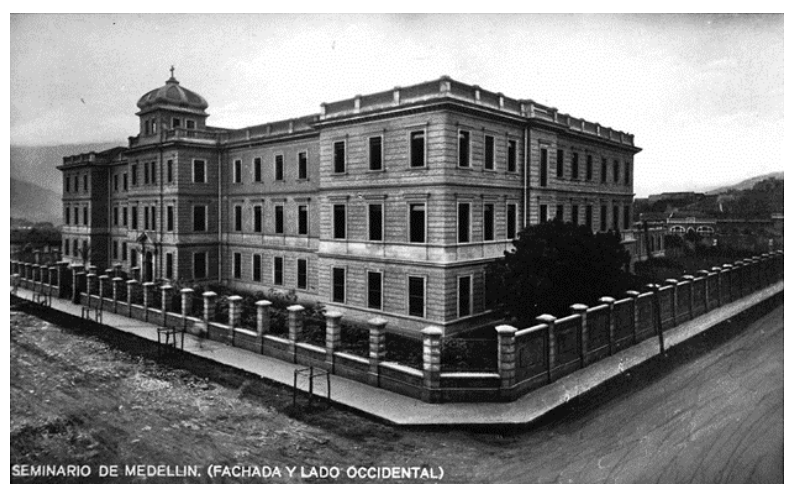

Figura 5. Seminario Mayor. Medellín. En la Monografía histórica del Seminario Conciliar, se define como "La obra destinada a vencer el rigor de los siglos y dedicada a la formación de sacerdotes".

Fuente: https://www.centrodemedellin.co/ ArticulosView.aspx?id $=253$

Hacia 1919, el hermano salesiano Giovanni Buscaglione inició, en la vecindad de la Catedral Metropolitana todavía en obra, la construcción del nuevo edificio para la sede del Seminario Mayor. Más tarde, en los años setenta, la construcción de la Avenida Oriental le quitó parte del terreno que lo rodea; la congestión y el bullicio del centro $-\mathrm{y}$ el valor del terreno y el edificio- animaron a la Arquidiócesis a trasladar el Seminario fuera de la ciudad, a la vecina localidad de Las Palmas.

Después de descartar la idea de convertir al edificio en un conjunto de apartamentos, en 1980 se inició la transformación del seminario en un centro comercial con el objetivo de tener una fuente de financiamiento para fines pastorales de la Iglesia. El proyecto contempló la construcción de locales, en los dos primeros pisos, kioscos en el patio y destinar el tercer piso para las oficinas de la curia. Sin embargo, no se tuvo en cuenta que los rituales de la religión católica, interiorizados en la comunidad antioqueña, entrarían en conflicto con el entretenimiento ligero, sin ceremonias, sin pretensiones ni reglas propias del consumo en los centros comerciales.

Byung-Chul Han (2018) enfatiza que esa falta de rituales que expresan la cohesión colectiva en los centros comerciales enfatiza el ego de los visitantes y señala también que es el comportamiento opuesto al de los asistentes a los templos en los que el ritual refuerza el sentido de pertenencia a la comunidad.

La presencia de la curia, los locales vendidos a otras parroquias del departamento de Antioquia, que pusieron comercios de artículos religiosos y las imágenes y símbolos del catolicismo presentes en el edificio, mantienen la antigua identidad y en una comunidad que tiene claramente identificado el comercio con el paseo (desde inicios de la modernidad) y la religiosidad con la pasión, no resulta fácil resemantizar un edificio del ritual católico y crear una realidad alternativa alrededor del consumo.

Villanueva nunca fue asumido por la comunidad como lugar de "entretenimiento"; curiosamente desde antes de terminar la transformación del seminario en centro comercial el entonces Cardenal López Trujillo afirmaba que se había hecho un "mal negocio"4; se entiende también que haya sido poblado por comercios poco atractivos para el "entretenimiento" como son los consultorios odontológicos, las ventas de insumos médicos y la emisora evangelizadora Radio María (1320 AM).

El Centro Comercial Villanueva no responde al significado de paseo que históricamente tuvo el comercio en Medellín y su desarrollo se vio frenado por el atractivo de los centros comerciales (shopping centers, malls) que se comenzaron a construir, en esos años, en los nuevos sectores al amparo de la moda y favorecidos por el clima primaveral de la ciudad, que permitía el paseo por recorridos en espacios cerrados o abiertos con la magnífica vegetación del lugar.

4. Referido en el informe sobre el Centro Comercial Villanueva en https://www.centrodemedellin.co/ArticulosView. aspx?id $=253$ 


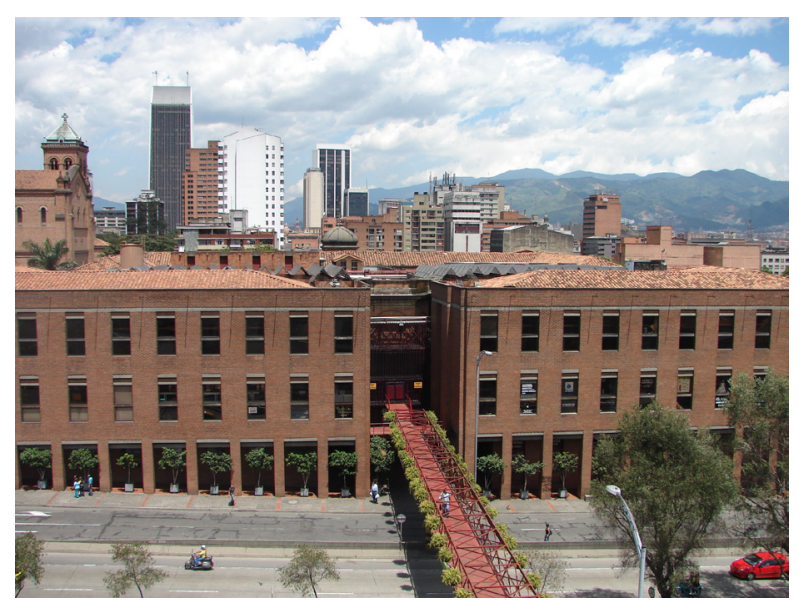

Figura 6. Centro Comercial Villanueva, esquina apacible en el bullicio y congestión del centro de Medellín; un puente peatonal facilita el acceso desde ambas aceras de la Avenida Oriental. Fuente: Edificio VillanuevaMedellín.jpg - Wikimedia Commons

Sin embargo, esta situación, junto con la declaración como monumento histórico por parte de la Oficina de Planeación Municipal en 1978, y luego, en 1991 como bien de interés municipal en nivel de conservación general, permitió preservar el edificio que es imagen de una época, identidad del espíritu del tiempo en un momento de la vida de la ciudad y es hito y referencia en el paisaje cultural urbano; por último, esta intervención insinúa una primera respuesta a las preguntas con que se cerró el punto anterior y es la importancia de lo colectivo, en este caso la pasión (la tradición religiosa del pueblo antioqueño) frente al entretenimiento individualista y vacío del consumo.

En el marco de ese deseo de modernidad, hay que enfatizar el pensamiento del gobernador de Antioquia y después presidente de la Nación, Pedro Nel Ospina, que trajo a la ciudad al arquitecto belga Agustín Goovaerts, que en 1924 presentó los planos para el Palacio Nacional. Terminado en 1933, el edificio contenía las oficinas del Estado Nacional, situación que se repitió -en esos años- en otras capitales en el marco de la integración del territorio colombiano. En 1988 fue declarado monumento nacional y en 1992, después de ser vendido a particulares, se iniciaron las obras para convertirlo en centro comercial.

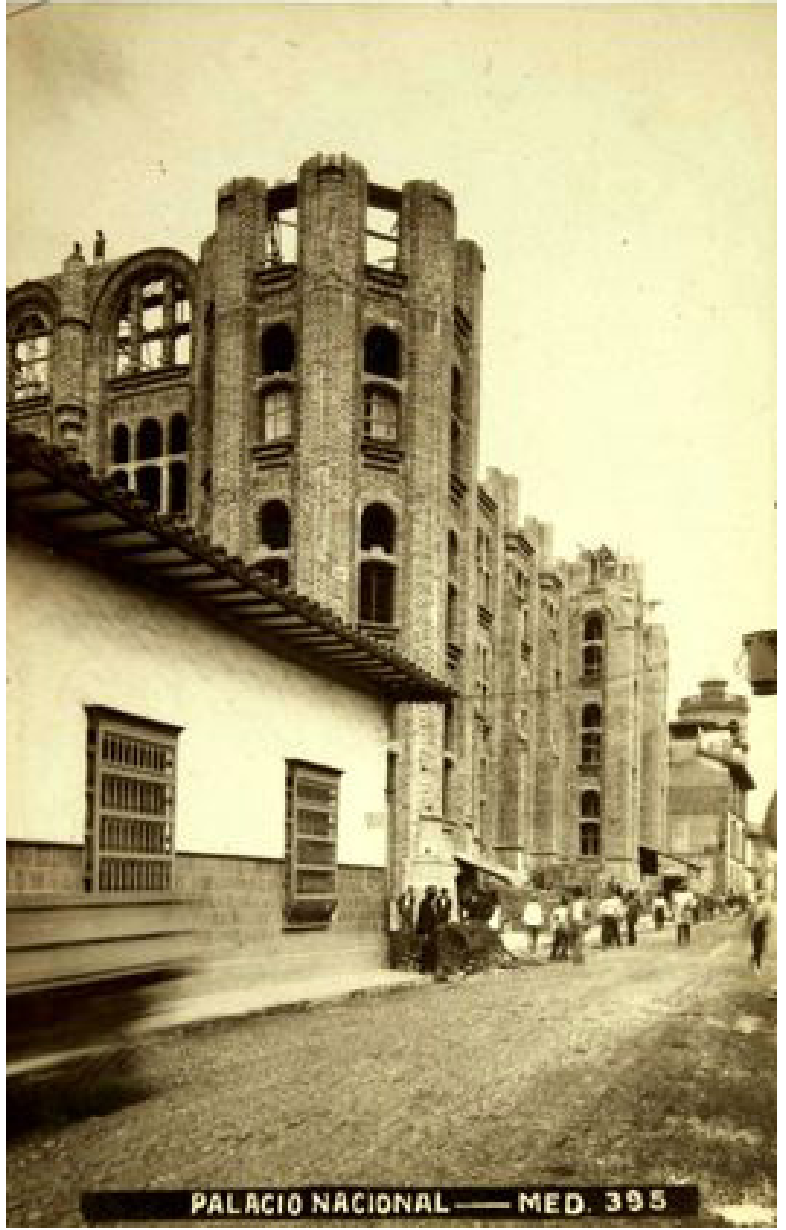

Figura 7. El Palacio Nacional en construcción, Medellín, fines de la década de 1920. La obra del belga Goovaerts expresa el deseo de modernidad del pueblo antioqueño y del gobierno de Pedro Nel Ospina.

Fuente: Gonzalo Escobar, en https:// www.centrodemedellin.co/ArticulosView. aspx?id=200

A diferencia de lo ocurrido con el Seminario Mayor, el edificio del Palacio Nacional no fue asumido por la comunidad como parte de sus rituales, dado que las ceremonias propias de los trámites administrativos son distantes, física y emocionalmente: por una parte, se identifican con Bogotá, la capital nacional, y, por otra, no hay participación comunitaria en la individualidad de los trámites. 
Ante esta débil significación colectiva, le fue fácil a la comunidad aceptar la resignificación de la obra como centro comercial, ubicada, además, en una zona de comercio popular de gran actividad como son las calles adyacentes, con la particularidad que el comercio popular basa su éxito en la idea del recorrido o "paseo" interiorizado por la comunidad desde principios del siglo XX y no en la idea de "entretenimiento".

Se señala que, ante la dificultad de la preservación del patrimonio arquitectónico en este contexto, la coincidencia de esos tres factores (bajo nivel significacional, entorno comercial del sector y tradición de la relación comercio-paseo) permitió su preservación, como imagen urbana y representación de la modernidad de la ciudad en los años veinte y treinta del siglo XX.

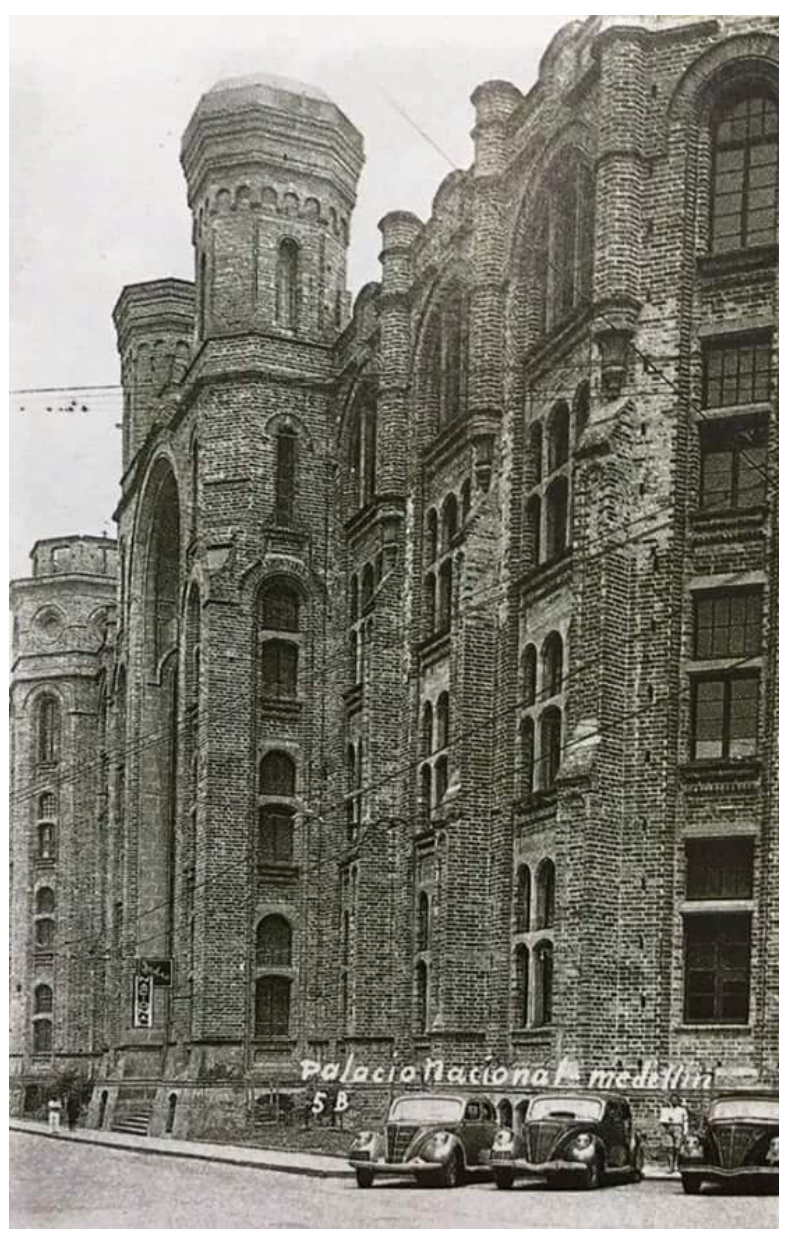

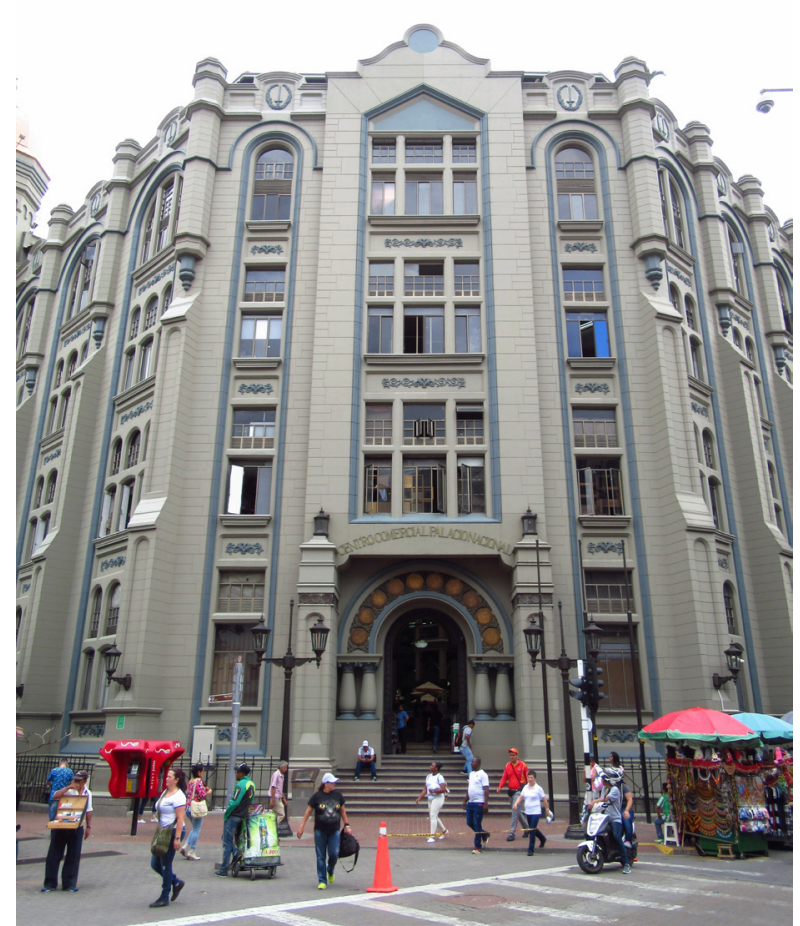

Figuras 8 y 9 . El revestimiento de una parte de la fachada, en la intervención del arquitecto Pedro $\mathrm{Nel}$ Gómez, ocultó la expresión original del ladrillo pero logró una excelente imagen urbana. Fuente: Medellín Travel y Felipe Restrepo Acosta Creative Commons.

\section{Sin Memoria, Significantes Demolidos y Significados Perdidos}

El Edificio Gonzalo Mejía nació como edificio urbano para albergar dos actividades estrechamente ligadas a la vida de la ciudad moderna: el hotel de lujo y el teatro, que satisfacía el deseo de modernidad de los ciudadanos, al hacerlos partícipes del mundo a través de las películas y los espectáculos internacionales que presentaba.

Su ubicación en la esquina de Junín con La Playa, la avenida que avanzaba cubriendo la tradicional quebrada Santa Elena confirma la vocación urbana del Edificio Mejía, lo mismo su cercanía a otros referentes de la ciudad moderna: el Club Unión y el Salón de Té Astor, ambos en la carrera Junín, eje comercial y social de Medellín de esos años. 


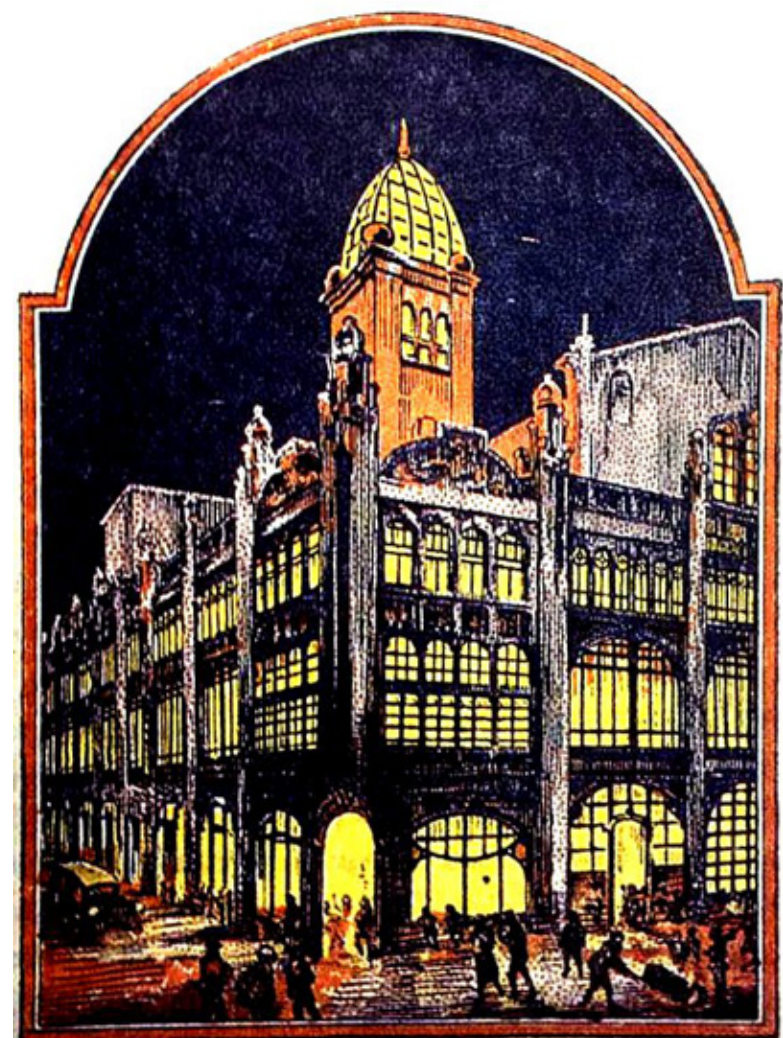

Figura 10. Esquina de la carrera Junín con La Playa, Medellín: la presencia urbana del Edificio Gonzalo Mejía, con el Hotel Europa y el teatro Junín. Agustín Goovaerts 1924. Fuente: memoria visual de medellin@gmail.com

En 1924 se inauguró el Edificio Mejía, Tal vez la obra más significativa de Agustín Goovaerts en Medellín ya que no se trataba de un encargo oficial, sino privado. Al respecto, Mercedes Lucía Vélez (1994, p.13) señala: El Teatro Junín-Hotel Europa es el edificio más transparente y liviano de estructura entre los construidos en su momento en Medellín, por su claridad estructural, la libertad de la secuencia de sus espacios y la sencillez de su fachada libre de ornamentos clásicos en la que la belleza depende de las cuidadas proporciones entre llenos y vacíos." Más adelante agrega: "'Todos los habitantes parecían orgullosos de esas fachadas que un arquitecto extranjero sobrepusiera sobre las tapias con aleros".
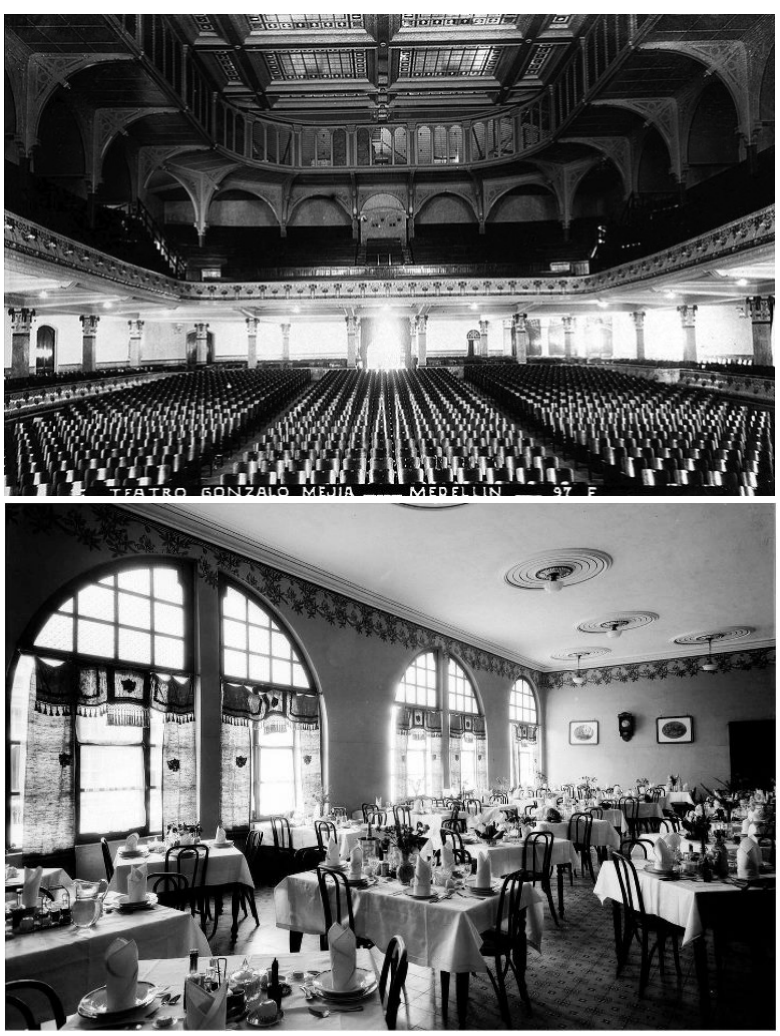

Figuras 11 y 12. Sala del Teatro Europa y restaurante del Hotel Junín. Fuente: memoria visual de medellin@gmail.com

El sueño burgués duró apenas cuarenta años; en la década de 1960 habían cambiado muchas cosas en Medellín; más allá de la vida burguesa otro sueño crecía en la comunidad: la industrialización y sus símbolos que alcanzaban al orgullo de toda la población. El desarrollo de la industria textil definió la nueva identidad de la ciudad; por otra parte, las clases sociales tradicionales abandonaron progresivamente el centro de Medellín y se ubicaron en los nuevos desarrollos alejados del centro. Para el nuevo pensamiento de la ciudad, el Edificio Mejía era un estorbo del pasado con el teatro -ya en decadencia- y el hotel Junín, que no podía competir con el monumental Hotel Nutibara, inaugurado en la década del cuarenta. La demolición era inevitable.

Los signos de la orgullosa burguesía medellinense y sus pioneros -como el mismo Gonzalo Mejíadesaparecían del contexto antioqueño y a nivel nacional se convertían en mitos, al tiempo que se consolidaban las imágenes de la sociedad industrial, una de las más pujantes y modernas de América. 
Una de esas imágenes, tal vez el signo más representativo de esa nueva sociedad fue el edificio de Coltejer, una de las más consolidadas industrias textiles, que se construyó en el lote donde había estado el Edificio Mejía, una torre de 36 pisos inaugurada en 1972. La comunidad, orgullosa de su nuevo símbolo identificó, la silueta del rascacielos, con una aguja... un símbolo de la industria textil.

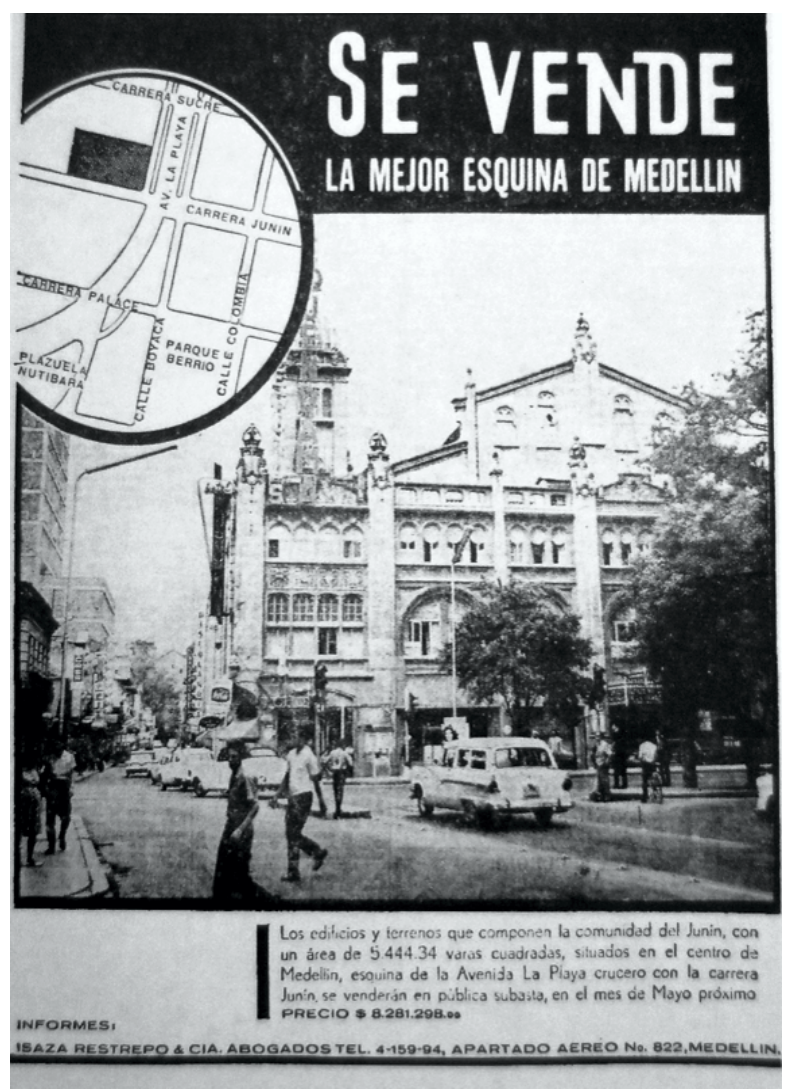

Figura 13. Triste aviso de prensa, el fin del Edificio Mejía: una muerte anunciada que a nadie importó. Fuente: Tomado de: 819158_1015140254397 1308_1945145716_o. Fecha de captura de la imagen 24 de junio de 2020.

En el texto El último poeta del Coltejer, Eliana Castro Gaviria (S.F), se refiere a un locutor del radioperiódico Clarín del 3 de octubre de $1967^{5}$ que anunciaba: "Es inevitable que se vaya el Teatro Junín porque la esquina donde está situado es la más valiosa y merece convertirse en una edificación suntuosa que caracterice el avance incontenible de la ciudad".

5. Citado en https://www.centrodemedellin.co/ArticulosView. aspx?id=276\&type $=$ A\&idArt $=277$
El 5 de octubre 1967, comenzó la demolición del Edificio Mejía con el Hotel Europa y el Teatro Junín, que cerró su ciclo con los balazos de Arizona Colt, una película de muy baja calidad, tratando de olvidar que por allí habían pasado en años recientes Marco Antonio Muñiz, Felipe Pirela y la orquesta de tangos de Roberto Caló. La esquina más valiosa de Medellín, como definió el locutor radial no sería para la memoria de una sociedad que, como pocas, es orgullosa de sus tradiciones; sería para el orgullo empresarial.

En ese momento no se advirtió que con la demolición del edificio Mejía se perdía un signo de identidad y si alguien lo hubiera advertido, quizás lo hubiera callado, ya que sobre la identidad antioqueña no caben dudas. Algunas veces creemos que la memoria va más allá de los signos, sin embargo la memoria se nutre de esos signos que son las marcas que hacen del lugar un "lugar de memoria" porque, como ya se indicó: haber tenido lugar es tener un lugar (Sztulwark P. 2006) o, lo que es lo mismo: haber sucedido es haber marcado un lugar.

\section{Hotel Granada, Bogotá}

El 15 de julio de 1947 la orquesta de Lucho Bermúdez se presentó en el Hotel Granada de Bogotá. Porros y cumbias invadieron las noches de la sociedad bogotana en competencia con los tradicionales pasillos y bambucos; porque la moda salía del Hotel Granada, el más elegante, el más sofisticado, la cara internacional de Bogotá en su esquina más representativa, allí donde se encuentran la antigua calle Real con la avenida Jiménez, construida sobre la canalización y entubamiento del río San Francisco. El hotel no solamente recibía los huéspedes que llegaban del extranjero, también era el sitio de encuentro de la sociedad bogotana, chismes de peluquería entre aromas de lacas y tinturas; discusiones políticas o de negocios en el bar; familias enteras en el restaurante. Por los salones del hotel pasó $-\mathrm{y}$ muchas veces se definió- la historia de Colombia y se guardaron infinidad de anécdotas que hicieron parte de la memoria de la ciudad.

Se inauguró en 1928, construido sobre un anteproyecto hecho en París por el arquitecto Diego Suárez Costa y adaptados por Alberto Manrique Martín, el mismo que en 1926 modificó la Plaza de Bolívar y creó el ámbito de las cuatro fuentes que fue imagen e identidad de la ciudad cachaca, la de 
gabardinas y tranvías, la que intuyó la frase menos es más como símbolo de buen gusto, mucho antes que lo dijera Mies van der Rohe y que lo practicaran los arquitectos modernos.

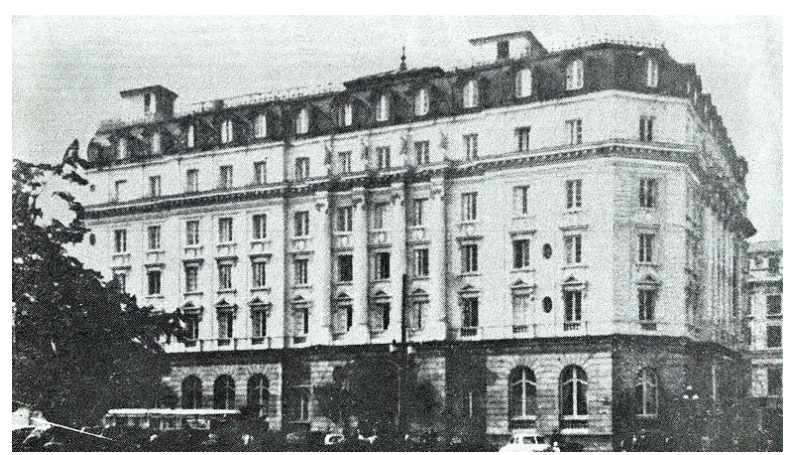

Figura 14. Hotel Granada y Parque de Santander, vista desde la carrera Séptima hacia la esquina de la avenida Jiménez, a la derecha, la torre de la iglesia de San Francisco. Fuente: Bogotá, estructura y principales servicios públicos.

En diagonal a la esquina del Hotel Granada, a principios del siglo $\mathrm{XX}$, cuando aún no estaba entubado el río y la calle real lo cruzaba por el puente San Francisco, el ingeniero español Manrique Canals, padre del arquitecto Manrique Martín construyó el Pasaje Rufino Cuervo, antecesor de los pasajes comerciales y pionero del comercio organizado en un espacio peatonal cubierto. Pero al igual que el Hotel Granada -y muchos años antes- el Pasaje Rufino Cuervo fue demolido

El Hotel Granada, que fue un representante de la ciudad cachaca en los años en que se consolidó su identidad; no desapareció con los incendios del 9 de abril de 1948, como ocurrió con el Hotel Regina, otro símbolo de aquella ciudad. Al igual que el tranvía, que desapareció en 1951 por iniciativa de un alcalde que tapó sus rieles, el Hotel Granada fue demolido en 1953 (Martínez,J., 1978). Es curioso, la ciudad que buscó y busca aún hoy su identidad demolió y acabó con sus símbolos, pero hay que comprenderla en su historia y en las muchas memorias en que se refugia.

Cuando los recuerdos son difíciles de asumir $-\mathrm{y}$ eso es, para muchos, el acontecimiento del 9 de abril- es preferible borrar los signos y aunque las presencias sobreviven a los signos, eso no ocurrió con el Hotel Granada, ni con el Regina, ni siquiera con las terrazas y balaustradas que Manrique Martín construyó en el Parque Santander entre ambos hoteles.
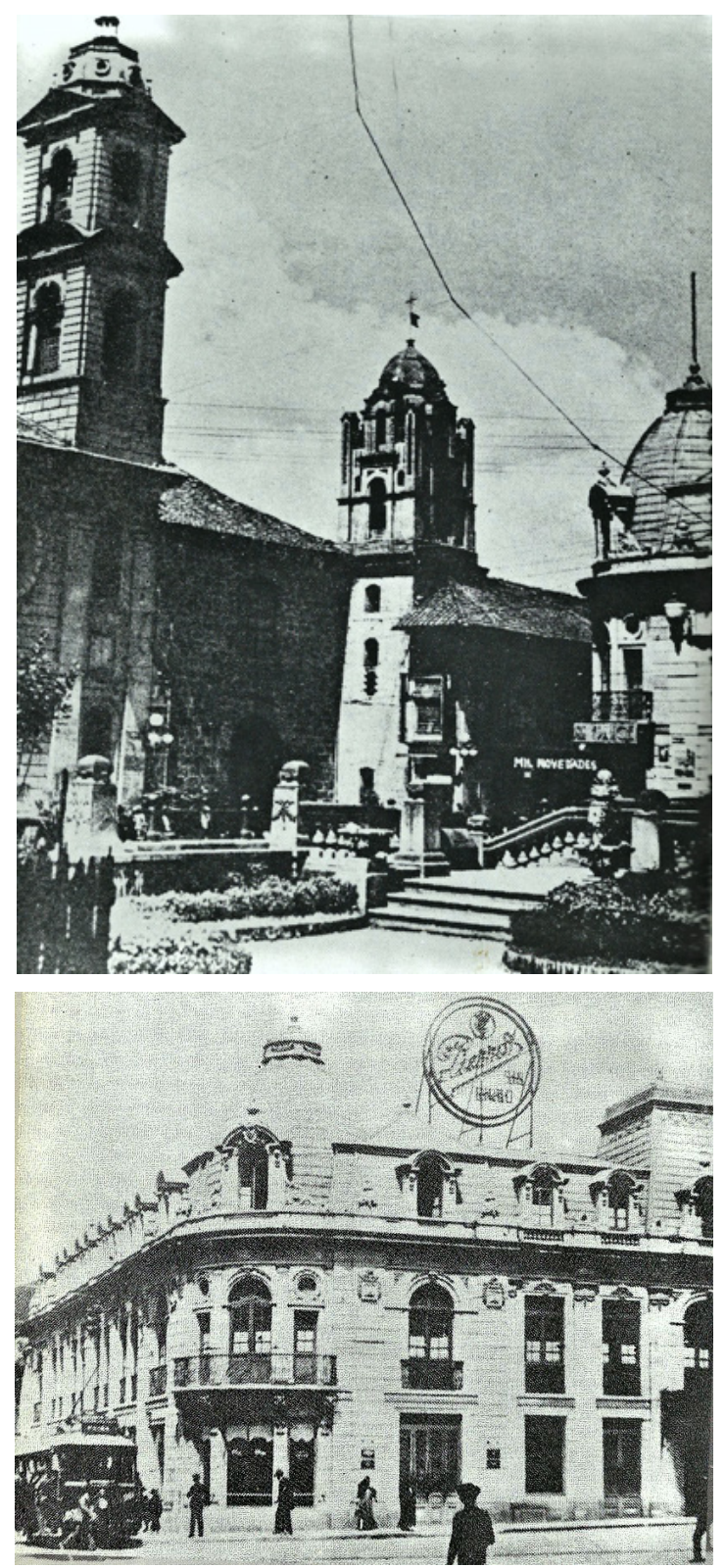

Figuras 15 y 16. Parque de Santander con las terrazas y balaustradas diseñadas por Alberto Manrique Martín, iglesias de la carrera Séptima y esquina del Hotel Regina. Fuente: Bogotá, estructura y principales servicios públicos.

Nacía una nueva Bogotá, la migración de una clase social tradicional del centro a los nuevos barrios en el norte de la ciudad, abandonó los símbolos de la tradicional Arquitectura de fuertes connotaciones de las escuelas de Bellas Artes, e intentó crear nuevos. Al igual que en los símbolos anteriores, en los nuevos también subyace el anhelo de modernidad, ahora expresado en la Arquitectura del 
Movimiento Moderno, en los postulados de la Carta de Atenas y el plan de Le Corbusier para Bogotá, que agregaban el concepto de funcionalidad al binomio sobriedad-buen gusto que dio la fuerte identidad de la "ciudad cachaca".

Sin embargo, ni las obras de los excelentes arquitectos modernos que tuvo la ciudad, ni las propuestas y las ideas que mostraba la revista Proa, enmarcadas en la Arquitectura y el urbanismo modernos, ni la confianza que esas imágenes generaban hacia un futuro mejor "con alegría y optimismo" (revista Proa, 1946) lograron dar una identidad tan fuerte y reconocible como la que tuvo la llamada "ciudad cachaca"

El Hotel Granada quedó amarrado a una época y a las prácticas de una sociedad que había cambiado y se desentendía de los viejos significantes; tal vez por eso no le importó que desaparecieran. El olvido los ocultó bajo el ansia de modernidad y la fascinación de lo nuevo. El edificio de Avianca borró la memoria del Hotel Regina y la imagen del poder empresarial ocultó los relatos cotidianos del centro de la ciudad. En 1958 se inauguró, en el lugar donde la estuvo el Hotel Granada, el nuevo edificio del Banco de la República; la falta de significados que esta construcción tuvo para la comunidad impidió las prácticas con este edificio que resulta ajeno al ir y venir de la vida bogotana por las dos principales avenidas del centro.

Por último, el Jockey Club también abandonó el marco del Parque Santander. El edificio republicano que en 1939 diseñó, para ese fin, el arquitecto Gabriel Serrano, emigró a una nueva sede en el norte de la ciudad. Era el último rasgo que quedaba en el espíritu del tiempo, el zeitgeist de aquella Bogotá cachaca de tranvías y gabardinas cada día más borrosa en la memoria de la ciudad.

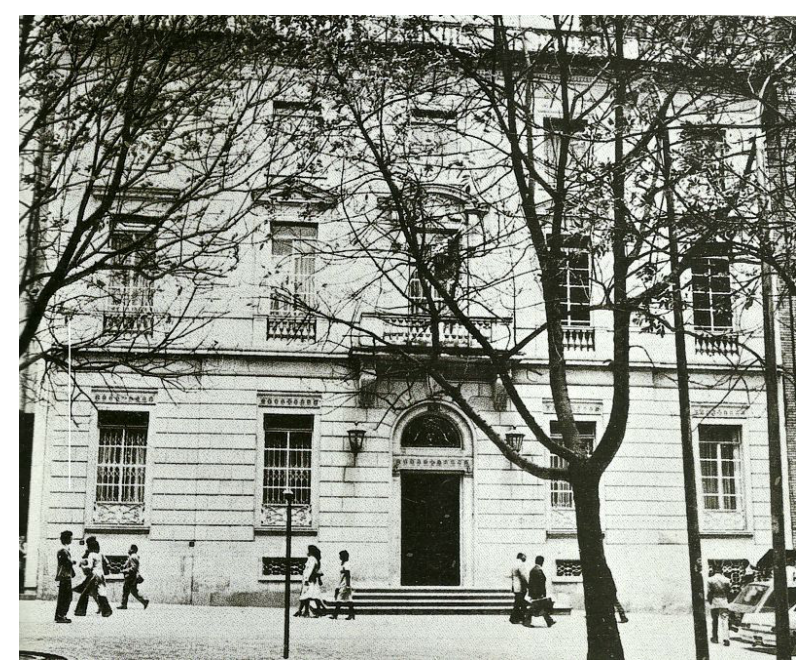

Figura 17. Fachada de Jockey Club frente al Parque Santander, en la carrera 6a No 15-18, Arq. Gabriel Serrano, 1939. Fuente: Bogotá, estructura y principales servicios públicos.

\section{CONCLUSIONES}

Las conclusiones producto de una etapa del proceso de investigación, son definitorias del interés y la orientación de la siguiente etapa. En este caso, la mirada a la relación memoria-patrimonio condujo a la reflexión sobre el deseo comunitario que encierra la obra patrimonial y se puede concluir que una obra arquitectónica o artística o un acontecimiento son reconocidos como patrimonio cuando tienen la capacidad de satisfacer un deseo colectivo; es decir, que llena el vacío de una faltante en la comunidad.

Esa conclusión en esta etapa de la investigación, lleva a mirar los elementos patrimoniales (la obra, el acontecimiento) como rasgos de identidad $y$, simultáneamente, observar el deseo colectivo que llevó a encontrar su satisfacción en esos elementos. Por último, la reflexión sobre el espíritu del tiempo, ese concepto que reúne los diferentes rasgos y manifestaciones culturales de un momento, muestra acontecimientos que producen quiebres en el devenir de una comunidad. Son procesos de rescate u olvido, que evidencian cambios en los deseos colectivos, que llevan a reafirmar o desconocer determinados bienes patrimoniales. 


\section{REFERENCIAS}

Baudrillard, Jean (1981). Cultura y simulacro. Kairós. Barcelona.

Borrega Reyes, Y. (2009) El patrimonio y su relación con el turismo https://www.facebook.com/CIESDE. Gestion.Cultural/photos/borrega-reyes-yolanda-el-patrimonio-y-su-relaci\%C3\%B3n-con-elturismoinstituto-de-inv/1474715282838422

Byung-Chul Han (2018) Buen Entretenimiento.Una deconstrucción de la historia occidental de la pasión. Herder Editorial. Barcelona.

Byung-Chul Han: "El dataísmo es una forma pornográfica de conocimiento que anula el pensamiento" César Rendueles 15-02-2020 El País, Cali / Babelia.

Castro Gaviria, Eliana (S.F.) El último poeta del Coltejer, Web page. Disponible en: https://www. centrodemedellin.co/ArticulosView.aspx?id=276\&type=A\&idArt=277

Centro de Medellín (S.F.) Palacio Nacional. Web site. Disponible en: https://www.centrodemedellin.co/ ArticulosView.aspx?id=200\&idArt $=200$

Centro de Medellín (S.F.) Villanueva. Web site. Disponible en: https://www.centrodemedellin.co/ArticulosView. aspx?id=253\&idArt $=253$

Covo, Adelina (2017). El adefesio de La Serrezuela II. Web site. Disponible en: https://www.las2orillas.co/eladefesio-de-la-serrezuela/Eco, Umberto (1993) Lector in fabula. Lumen, Barcelona

Fainstein, S. \& Gladstone, D. (1999). Evaluating urban tourism. In D. Judd and S. Fainstein (Eds.), The Tourist City. New Haven, CT: Yale University Press, 21-34.

Halbwachs, Maurice, (1992).On collective memory. The University of Chicago.

Lash,Scott M, Urry, John (1997) Reflexive modernization: The aesthetic dimension . Sage Publications, Newbury Park. CA.

Londoño Vélez Patricia (1995) La religión en Medellín 1850-1950: la vida devota y su proyección popular. Web site. Disponible en: https://www.banrepcultural.org/

Mansilla Decesari, E. C. (2011) La memoria en la trama urbana de las ciudades. Aletheia, volumen 2, número 3, noviembre 2011. http://www.memoria.fahce.unlp.edu.ar/art revistas/pr.5010/pr.5010.pdf.

Martínez Jiménez C. (1978) Bogotá, estructura y principales servicios. Cámara de Comercio de Bogotá.

Nora, Pierre (2008) Les Lieux de mémoire-Los Lugares de la memoria. Ediciones Trielce. Montevideo.

Palacios María Cecilia (2010) Turismo, políticas y ligares de memoria: el caso de las publicaciones turísticas del Gobierno de la ciudad de Buenos Aires (1983-2007) https://perio.unlp.edu.ar/ojs/index.php/question/ article/view/722

Pérgolis, J.C. (2000). Estación Plaza de Bolívar: Una mirada desde la semiótica del deseo a la ciudad y su plaza. Bogotá: Alcaldía Mayor de Bogotá. 
Pérgolis J.C. (1995) Las otras ciudades. UN Ediciones. Universidad Nacional de Colombia. Bogotá.

Pérgolis Valsecchi J. C., \& Quijano Gómez E. (2019). Memoria, acontecimiento, objeto y lugar. Procesos Urbanos, 6(6), 13-21. Recuperado a partir de https://revistas.cecar.edu.co/index.php/procesosurbanos/article/view/453

Pérgolis, J.C. (2014) El deseo de modernidad en las ciudades republicanas en Colombia. U. Católica de Colombia .Bogotá.

Revista Proa No3 (octubre 1946).Recuperado de: http://banrepcultural/org/sites/default/iles/proa003.pdf

Rodríguez, Guillermo (2012). Cartagena de Indias: La Serrezuela, una Plaza con historia que termina. Blog. Disponible en: http://deltoroalinfinito.blogspot.com/2012/10/cartagena-de-indias-la-serrezuela-una. $\underline{\text { html }}$

Romano, Marco: (1989) "Cittadini senza città" en Le città del mondo e il futuro delle metropopli. Electa, Milán.

Somospartedelcuento (2012). 15 años de vida y muerte del Festival de Música del Caribe, la rumba más grande de Cartagena. Blog. Disponible en: https://somospartedelcuento.wordpress.com/2012/04/24/15anos-de-vida-y-muerte-del-festival-de-musica-del-caribe-la-rumba-mas-grande-de-cartagena/

Sztulwark P. (2006). Ciudad, memoria, monumento, lugar y situación urbana. En: Summa+ №. 81, 2006.

Vélez White Mercedes Lucía (1994) Agustín Goovaerts y la Arquitectura en Medellín. Ed. El Propio Bolsillo. Medellín 